\title{
PECULIARITIES OF THE MORPHOMETRIC PARAMETERS OF SUPRAHYOID REGION OF THE HUMAN PREFETUSES
}

DOI:10.36740/WLek202102122

\author{
Olexandr V. Tsyhykalo' , Nataliia B. Kuzniak' , Pavlo P. Perebyjnis' ', Svitlana I. Boitsaniuk², Iryna Ya. Tsvyntarna², \\ Angelina M. Servatovych ${ }^{2}$ \\ 'BUKOVINIAN STATE MEDICAL UNIVERSITY, CHERNIVTSI, UKRAINE \\ 2. HORBACHEVSKY TERNOPIL NATIONAL MEDICAL UNIVERSITY, TERNOPIL, UKRAINE
}

\begin{abstract}
The aim: To determine the peculiarities of the morphometric parameters of suprahyoid region of the human prefetuses.

Materials and methods: Thirty specimens of human prefetuses of 14.0-80.0 mm parietococcygeal length ( $P C L)$ (7-12 weeks of IUD) were studied using a complex of modern methods of morphological research.

Results: 0 the basis of obtained digital indicators of the main morphometric parameters of human SHR in the dynamics of the prenatal period of IUD the critical periods of development of the region were clarified and mathematical functions that describe the normal course of organogenesis of SHR were created, which can be useful for creating diagnostic algorithms for the norm when carrying out prenatal diagnostics and monitoring the state of the fetus. It has been established that the 9-10 th week of IUD is a critical period in the development of SHR, since during this time, intensive growth processes occur, which are manifested by a sharp change in the size of the organ, and this can lead to the appearance of variants of the structure and possible congenital defects of the SHR and the dental-maxillary apparatus in general.

Conclusions: 1.Age-depended dynamics of changes in the anterior angle of the SHR shows an almost linear decrease in the angle by the end of the 9th week of IUD almost to $76^{\circ}$, after which it increases to almost $90^{\circ}$ by the end of the 10th week. From the 11 th week of the IUD, the anterior angle decreases again to $77^{\circ}$, but begins to increase at the 12th week and by the end of the prefeal period. 2.The lateral length of SHR increases almost uniformly until the 9 th week of IUD, during which its growth rate slows down. Starting from the end of the 10th week of IUD, this morphometric parameter begins to grow rapidly until the end of the prenatal period of ontogenesis. The growth rate of the lateral length of the SHR is described by the function: $L$ lat $=1.1025+0.0015 x+0.001 x^{2}$. 3.The width of the SHR from the 10th week of IUD begins to grow rapidly until the end of the prenatal period of development. The growth rate of the width of SHR is described by the function: $W=1.1025+0.0015 x+0.001 x^{2}$. 4. Analysis of the age dynamics of the area of SHR demonstrates the exponential dependence on the age of the prefetuses, which is described by a mathematical function: $A=1,2452 \exp (0,0424 x)$. Meanwhile, there is a slight slowdown in its growth rate at the 10th week of IUD with subsequent recovery of growth by the end of the prenatal period of ontogenesis. 5 .The $9-10^{\text {th }}$ week of IUD is a critical period in the development of SHR, since during this time, intensive growth processes occur, which are manifested by a sharp change in the size of the mandible.
\end{abstract}

KEY WORDS: anterior cervical region, suprahyoid triangle of the neck, prefetus, prenatal ontogenesis, human

Wiad Lek. 2021;74(2):291-294

\section{INTRODUCTION}

Finding out the features of morphogenesis and topographic changes of suprahyoid region (SHR) of the neck and its structures in the dynamics of human intrauterine development (IUD) remains a relevant area of morphological research [1-5]. Refined, comprehensive data on gender, age and constitutional features of the structure and topography of organs and structures of the SHR of the neck during the prenatal period of human ontogenesis will make it possible to develop new criteria for the interpretation of medical diagnostic imaging data, the degree of fetal viability, improve existing and develop new methods of surgical correction of congenital neck defects [6-9].

\section{THE AIM}

To determine the peculiarities of the morphometric parameters of suprahyoid region of the human prefetuses.

\section{MATERIALS AND METHODS}

Thirty specimens of human prefetuses of $14.0-80.0 \mathrm{~mm}$ parietococcygeal length (PCL) (7-12 weeks of IUD) were studied using a complex of modern methods of morphological research: anthropometry, morphometry, three-dimensional reconstruction and statistical analysis. The morphometric parameters of SHR were determined: width (distance between the inner surfaces of the angles of the mandible), anteroposterior length (distance from the anterior surface of the hyoid bone to the lower edge of the mental symphysis), lateral length (length of the lateral border of the SHR - distance from the inner surface of the angle of mandible to the lower edge of the mental symphysis), the anterior angle of the SHR (the angle between the lateral borders of the SHR). The area of the supralingual area was determined by the morphometric parameters of the sides and the width of the SHR. 


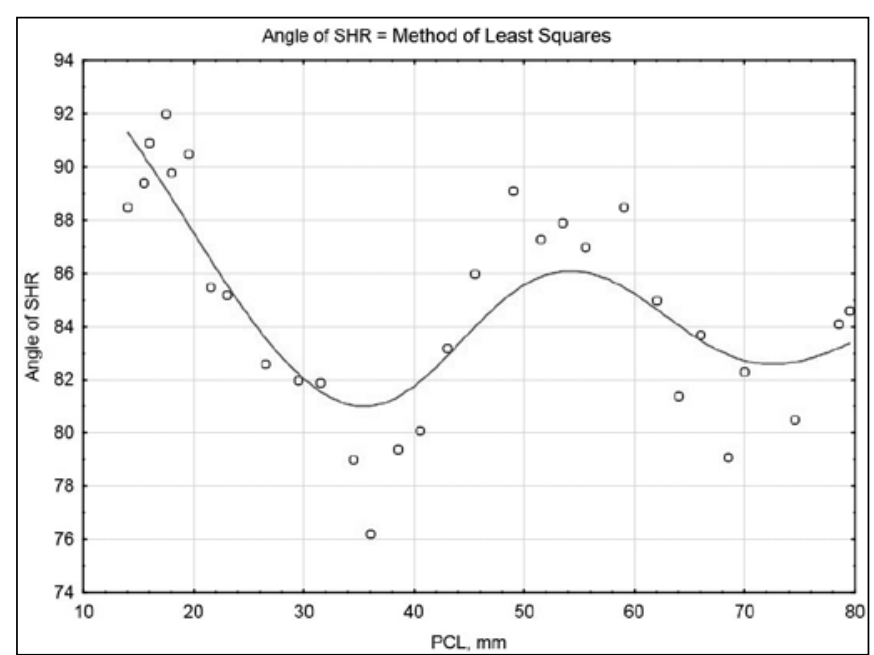

Fig. 1. The dynamics of changes of the anterior angle of the suprahyoid region in the prenatal period of human ontogenesis. Method of Least Squares.

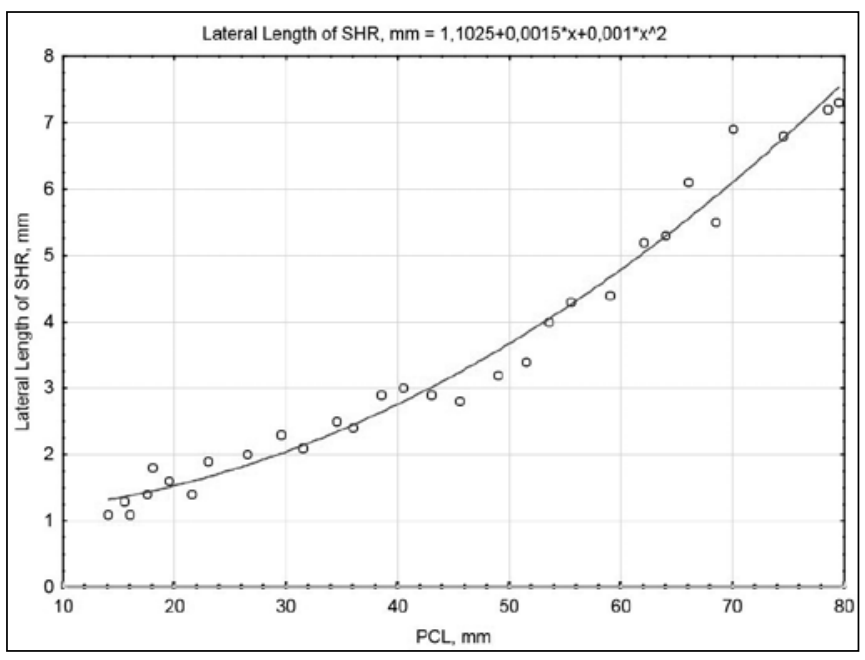

Fig. 2. Dynamics of changes in the lateral length of the suprahyoid region in the prenatal period of human ontogenesis. Polynomial dependence on age.

\section{RESULTS}

Analysis of the dynamics of morphometric parameters of the SHR of the neck allows to determine the features of their temporal changes, their possible unevenness during the prenatal period of human ontogenesis. Each of the parameters affects the area of the SHR, which is close to triangular in shape, and the size of the anterior angle and the width of the SHR are interrelated in a particular person - the greater the angle, the greater the width of the SHR, and vice versa. The clinical and diagnostic value of the area, which can be determined during ultrasound, is to predict malformations and variants of the structure of the mandible and anterior cervical region. Normative indicators of the size of the SHR and its area in the different terms of the prefetal period of IUD are morphological basis for the development of diagnostic algorithms for the interpretation of medical diagnostic imaging data. On the basis of obtained digital indicators of the main morphometric parameters of human SHR in the dynamics of the prenatal period of IUD the critical periods of development of the region were clarified and mathematical functions that describe the normal course of organogenesis of SHR were created, which can be useful for creating diagnostic algorithms for the norm when carrying out prenatal diagnostics and monitoring the state of the fetus.

Analysis of the age dynamics of changes in the anterior angle of the SHR by the method of Least Squares shows an almost linear decrease in the angle by the end of the 9th week of IUD almost to $76^{\circ}$, after which it increases to almost $90^{\circ}$ by the end of the 10th week (Fig. 1). From the 11th week of the IUD, the anterior angle decreases again to $77^{\circ}$, but begins to increase at the 12 th week and by the end of the prefeal period. In our opinion, this feature of fluctuations in the magnitude of the anterior angle during the prenatal period of ontogenesis is explained by the processes of structural rearrangement of Meckel's cartilage during the development of bone tissue and the formation of the mandible.

The lateral length of SHR increases almost uniformly until the 9th week of IUD, during which its growth rate slows down (Fig. 2). Starting from the end of the 10th week of IUD, this morphometric parameter begins to grow rapidly until the end of the prenatal period of ontogenesis. We explain the deceleration in the growth of the lateral length of the SHR at the 9th week of IUD by the end of the main processes of mandibular formation (intensive ossification of the bony base of the organ on the cartilaginous model, which is reduced during this period).

The growth rate of the lateral length of the SHR is described by the function:

$\mathrm{L}$ lat $=1.1025+0.0015 \mathrm{x}+0.001 \mathrm{x}^{2}$,

Where $\mathrm{L}$ lat is the lateral length in $\mathrm{mm}$,

$\mathrm{x}-\mathrm{PCL}$ in $\mathrm{mm}$.

The width of the SHR is the distance between the inner surfaces of the angles of the mandible, measured along an arcuate line that passes in front of the body of the hyoid bone. Analysis of the dynamics of changes in this parameter of the IHR shows a polynomial dependence on the age of the prefetuses (Fig. 3). At first there is a moderate growth rate of this parameter, from the 10th week of IUD the width of the SHR begins to grow rapidly until the end of the prenatal period of development. We believe that this feature of age morphometric dynamics is associated with structural changes in the mandible, which last until the 10th week, after which there are mainly processes of organ growth.

The growth rate of the width of SHR is described by the function:

$\mathrm{W}=1.1025+0.0015 \mathrm{x}+0.001 \mathrm{x}^{2}$,

Where $\mathrm{W}$ is the width of SHR in $\mathrm{mm}$.

$\mathrm{x}-\mathrm{PCL}$ in $\mathrm{mm}$.

Analysis of the age dynamics of the area of SHR demonstrates the exponential dependence on the age of the prefetuses, which is described by a mathematical function:

$A=1,2452 \exp (0,0424 x)$,

Where $\mathrm{A}$ is the area of SHR in $\mathrm{mm}^{2}$,

$\mathrm{x}-\mathrm{PCL}$ in $\mathrm{mm}$.

Meanwhile, there is a slight slowdown in its growth rate at the 10th week of IUD with subsequent recovery of growth by the end of the prenatal period of ontogenesis.

Thus, it can be argued that the $9-10^{\text {th }}$ week of IUD is a critical period in the development of SHR, since during this time, intensive growth processes occur, which are manifested by a 


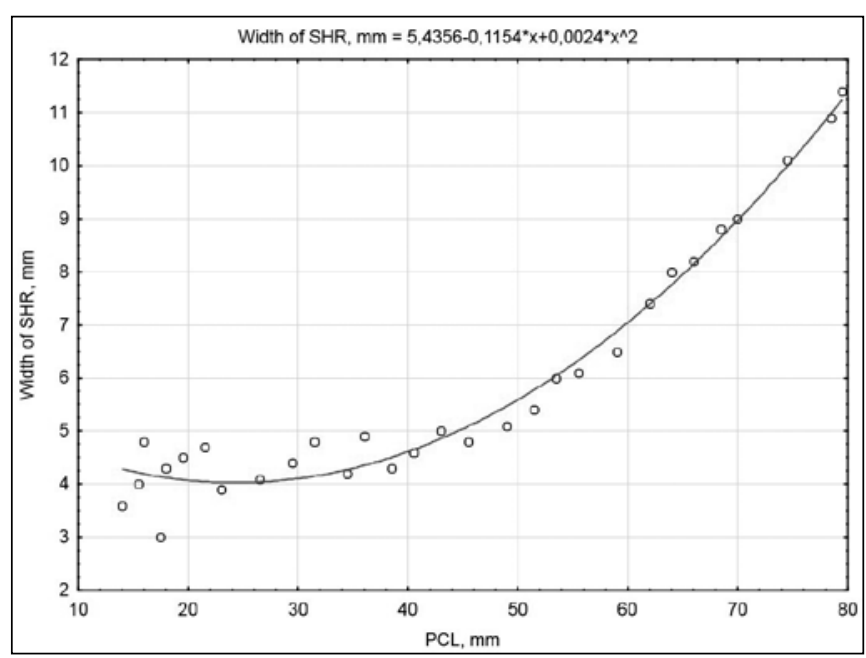

Fig. 3. Dynamics of changes in the width of the suprahyoid region in the prenatal period of human ontogenesis. Polynomial dependence on age.

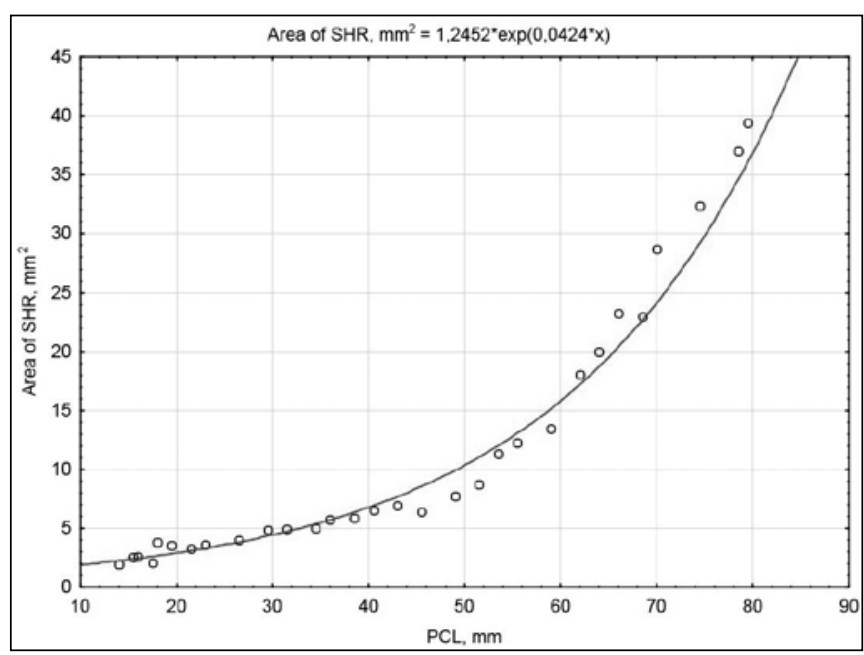

Fig. 4. Dynamics of changes of the area of the suprahyoid region in the prenatal period of human ontogenesis. Exponential dependence on age.

sharp change in the size of the mandible, and this can lead to the appearance of variants of the structure and possible congenital defects of the SHR and the superior neck region in general.

\section{DISCUSSION}

In our study the development of the structures of the suprahyoid region of the neck successively in the age-related dynamics of prenatal development has been studied by means of a complex of morphological methods. The method of $3 \mathrm{D}$ reconstruction of a series of consecutive histological sections of the head and neck, microscopic examination of our material and morphometry of suprahyoid triangles was widely used.

The majority of scientific studies of prenatal development of the suprahyoid triangles is limited to a certain age period. We have investigated the development of the SHR during a fairly long and important period of human development - from 7 th to 12th weeks. It is during this period that complex processes of morphogenesis of the mandible and neck muscles, formation of definitive topographic-anatomical relationships take place, which is emphasized by other researchers in this area $[1,3,10,11]$. A characteristic feature of the development of suprahyoid muscular triangles of the neck is the uneven growth of their morphometric parameters, due to the different growth rates of the structures that limit it. The morphometric parameters of the SHR were studied at different times by different methods of medical diagnostic imaging, as well as by the method of preparations and measuring the specimens $[9,11,12,13,14]$. Particular attention should be paid to the periods of slow or accelerated growth of morphometric parameters of the SHR found by many researchers. Scientists believe that it is during periods of uneven growth of structures that are in close syntopic connection, it is possible to develop variants of the structure of the SHR, as well as the occurrence of congenital malformations $[14,15]$. Therefore, we paid attention to the peculiarities of the growth of such indicators as the dynamics of changes in the anterior angle, the length of the lateral border, the width and area of the SHR. Analysis of spatio-temporal changes in morphometric parameters allowed to derive mathematical functions that describe the normal course of morphogenesis in the prenatal period of IUD, and their comparison on a time scale allowed to determine possible morphological causes of certain morphometric features of morphogenesis.

In our opinion, the age-speciphic dynamics of changes in the morphometric parameters of the SHR in human prefetuses depends primarily on the peculiarities of the development of the mandible and suprahyoid muscles during this period, as indicated in other studies $[16,17]$.

Radlanski R.J. et al. [10] note that at the beginning of the prefetal period of IUD, and in fact, at the end of the embryonic period - in embryos of 11.0-12.0 mm PCL (end of the 6th week of IUD) - all muscles are clearly differentiated and enlarged by size. By the beginning of the 7th week of IUD, the Meckel's cartilage is already bent upwards and the places of attachment to their lower edge of the mylohyoid, geniohyoid ra mylohyoid muscles [18]. At this age, the muscles of the suprahyoid group acquire definitive attachment sites due to the intensive development of the osseous model of mandible and the gradual involution of the Meckel cartilage [19]. In our opinion, it is the intensity of these morphologically opposite processes can significantly affect the shape of the mandible, and hence the morphometric parameters of the whole region.

We have identified critical periods of SHR development, which are predominantly 9-10 weeks of IUD. Radlanski R.J. et al. [10, 11], Levihn W.C. [13] also reported a significant increase in the size of the maxilla and mandible between the second and third trimesters of gestation, and therefore, in fact, the corresponding changes in the growth rates of morphometric parameters of the suprahyoid cervical triangles.

The mathematical functions obtained by us, which describe the normal course of organogenesis of the SHR, can be useful for the creation of diagnostic algorithms of the norm in the prenatal diagnosis of malformations of the neck and head, as well as for monitoring the condition of the fetus.

\section{CONCLUSIONS}

1. Age-depended dynamics of changes in the anterior angle of the SHR shows an almost linear decrease in the 
angle by the end of the 9 th week of IUD almost to $76^{\circ}$, after which it increases to almost $90^{\circ}$ by the end of the 10 th week. From the 11th week of the IUD, the anterior angle decreases again to $77^{\circ}$, but begins to increase at the 12th week and by the end of the prefeal period.

2. The lateral length of SHR increases almost uniformly until the 9th week of IUD, during which its growth rate slows down. Starting from the end of the 10th week of IUD, this morphometric parameter begins to grow rapidly until the end of the prenatal period of ontogenesis. The growth rate of the lateral length of the SHR is described by the function: $\mathrm{L}$ lat $=1.1025+0.0015 \mathrm{x}+0.001 \mathrm{x}^{2}$.

3. The width of the SHR from the 10th week of IUD begins to grow rapidly until the end of the prenatal period of development. The growth rate of the width of SHR is described by the function: $\mathrm{W}=1.1025+0.0015 \mathrm{x}+0.001 \mathrm{x}^{2}$.

4. Analysis of the age dynamics of the area of SHR demonstrates the exponential dependence on the age of the prefetuses, which is described by a mathematical function: $A=1,2452 \exp (0,0424 x)$. Meanwhile, there is a slight slowdown in its growth rate at the 10th week of IUD with subsequent recovery of growth by the end of the prenatal period of ontogenesis.

5. The $9-10^{\text {th }}$ week of IUD is a critical period in the development of SHR, since during this time, intensive growth processes occur, which are manifested by a sharp change in the size of the mandible.

\section{REFERENCES}

1. Begnoni G.,Serrao G., Musto F. et al. Craniofacial structures'development in prenatal period: An MRI study. Orthodontics \& craniofacial research. 2018;21(2):96-103.

2. BojchukT.M., Tsyhykalo 0.V., Kashperuk-KarpukI.S., TovkachYu.V. Embryology and Clinical Anatomy of the Neck. Chernivtsi: Meduniversity. 2016:88.

3. Gamss C., Gupta A., Chazen J.L., Phillips C.D. Imaging evaluation of the suprahyoid neck. Radiologic Clinics. 2015;53(1): 133-144.

4. Ericsson R., Knight R., Johanson Z. Evolution and development of the vertebrate neck. Journal of Anatomy. 2013;222(1):67-78.

5. Som P.M., Laitman J.T. Embryology, variations, and innervations of the human neck muscles. Neurographics. 2017;7(3):215-242.

6. Zavalyy M.A., Plaksyvyy A.H., Balabantsev A.H. Taktyka lechenyya bol'nykh s travmatycheskymy y vospalytel'nymy zabolevanyyamy shey. Klinichna anatomiya ta operatyvna khirurhiya. 2014;3:45-47. (in Ukrainian).

7. Horbatyuk 0.M., Makedons'kyy I.A., Kurylo H.V. Suchasni stratehiyi diahnostyky, khirurhichnoyi korektsiyi ta profilaktyky vrodzhenykh vad rozvytku u novonarodzhenykh. Neonatolohiya, khirurhiya ta perynatal'na medytsyna. 2019;9(4 (34)):88-97. (in Ukrainian).

8. Shimizu M., Weerawanich W. Sonographic diagnosis in the head and neck region: from an educational lecture presented at the 56 th General Assembly and Annual Scientific Congress of the Japanese Society for Oral and Maxillofacial Radiology. Oral radiology. 2019;35(2):101-126.

9. Elfeshawy M.S., Aly W.E., Abouzeid M.A. The Role of 3D \& 4D Ultrasonography in Diagnosis of Fetal Head and Neck Congenital Anomalies. International Journal of Medical Imaging. 2019;7(4):81.

10. Radlanski R.J., Renz H., Tabatabai A. Prenatal development of the muscles in the floor of the mouth in human embryos and fetuses from 6.9 to $76 \mathrm{~mm}$ CRL. Annals of Anatomy-Anatomischer Anzeiger. 2001;183(6):511-518.
11. Radlanski R.J., Kjær I., Vastardis H., Renz H. Morphometrische untersuchungen zur fetalentwicklung der menschlichen mandibula. Fortschritte der Kieferorthopädie. 1994; 55(2):77-83.

12. Esenlik E., Sener E.H., Yılmaz H.H., Malas M.A. Cephalometric investigation of craniomaxillofacial structures during the prenatal period: a cadaver study. Am J Orthod Dentofac Orthop. 2014;145:217227.

13. Levihn W.C. A cephalometric roentgenographic cross-sectional study of the craniofacial complex in fetuses from 12 weeks to birth. Am J 0 rthod. 1967;53:822-848.

14. Arangio P., Manganaro L., Pacifici A. et al. Importance of fetal MRI in evaluation of craniofacial deformities. J Craniofac Surg. 2013;24:773776.

15. Kamibayashi L.K., Richmond F.J. Morphometry of human neck muscles. Spine. 1998; 23(12):1314-1323.

16. Kusniak N.B., Palis S.Yu., Tsyhykalo 0.V. Peculiarities of morphogenesis and variant anatomy of the mandible in human fetuses. Development and modernization of medical science and practice: experience of Poland and prospects of Ukraine. Collective monograph. Vol. 3. Lublin: Izdevnieciba “Baltija Publishing", 2017:71-89.

17. Som P.M., Laitman J.T. Embryology, variations, and innervations of the human neck muscles. Neurographics. 2017; 7(3):215-242.

18. Trenouth M.J. Relative growth of the human fetal skull in width, length and height. Arch Oral Biol. 1991;36:451-456.

19. Kastamoni Y., Dursun A., Sanli O.C. et al. Morphometric development of the mandible in fetal cadavers. Journal of Craniofacial Surgery. 2020; 31(7):2036-2039.

\section{ORCID and contributionship:}

Olexandr V. Tsyhykalo: 0000-0003-2302-426X A, B,D

Nataliia B. Kuzniak: 0000-0002-4020-7597 A,D

Pavlo P. Perebyjnis: 0000-0002-8956-2426 B, C, D

Svitlana I. Boitsaniuk: 0000-0001-7742-1346 ${ }^{B, E}$

Iryna Ya. Tsvyntarna: 0000-0002-4251-5411 C, F

Angelina M. Servatovych: 0000-0002-8616-4385 F

\section{Conflict of interest:}

The Authors declare no conflict of interest.

\section{CORRESPONDING AUTHOR}

Olexandr V. Tsyhykalo

Bukovinian State Medical University

4 Teatralva Sq. 58001, Chernivtsi, Ukraine

tel: +380990737261

e-mail: tsyhykalo@icloud.com

Received: 27.08 .2020

Accepted: 04.01.2021

A - Work concept and design, B - Data collection and analysis, C - Responsibility for statistical analysis,

D-Writing the article, $\mathbf{E}$-Critical review, $\mathbf{F}-$ Final approval of the article 